\title{
Financial Quality Control of In-Patient Chemotherapy in Germany: Are Additional Payments Cost-Covering for Pharmaco-Oncological Expenses?
}

\author{
Volker R. Jacobs Peter Mallmann \\ Frauenklinik (OB/GYN), University Clinic of Cologne, Cologne, Germany
}

\section{Keywords}

In-patient chemotherapy · Hospital economics · Cost-revenue calculation . German diagnose-related groups (G-DRGs) . Additional in-patient payment

\section{Summary}

Background: Cost-covering in-patient care is increasingly important for hospital providers in Germany, especially with regard to expensive oncological pharmaceuticals. Additional payments (Zusatzentgelte; ZE) on top of flat rate diagnose-related group (DRG) reimbursement can be claimed by hospitals for in-patient use of selected medications. To verify cost coverage of in-patient chemotherapies, the costs of medication were compared to their revenues. Method: From January to June 2010, a retrospective costrevenue study was performed at a German obstetrics/gynecology university clinic. The hospital's pharmacy list of inpatient oncological therapies for breast and gynecological cancer was checked for accuracy and compared with the documented ZEs and the costs and revenues for each oncological application. Results: $N=45$ in-patient oncological therapies were identified in $n=18$ patients, as well as $n=7$ bisphosphonate applications; $\mathrm{n}=11$ ZEs were documented. Costs for oncological medication were $€ 33,752$. The corresponding ZE revenues amounted to only $€ 13,980$, resulting in a loss of $€ 19,772$. All in-patient oncological therapies performed were not cost-covering. Data discrepancy, incorrect documentation and cost attribution, and process aborts were identified. Conclusions: Routine financial quality control at the medicine-pharmacy administration interface is implemented, with monthly comparison of costs and revenues, as well as admission status. Non-cost-covering therapies for in-patients should be converted to out-patient therapies. Necessary adjustments of clinic processes are made according to these results, to avoid future losses.

\author{
Schlüsselwörter \\ Stationäre Chemotherapie · Krankenhauswirtschaftlichkeit . \\ Kosten-Erlös-Kalkulation · G-DRGs · Stationäres Zusatz- \\ entgelt (ZE)
}

\section{Zusammenfassung}

Hintergrund: Kostendeckende stationäre Therapie ist von steigender Bedeutung für Krankenhäuser in Deutschland, insbesondere bei teuren onkologischen Medikamenten. Zusätzliche Vergütungen (Zusatzentgelte; ZE) neben der pauschalen diagnosebezogene Fallgruppen (DRG)-Vergütung können von Krankenhäusern bei ausgewählten Medikamenten im stationären Einsatz geltend gemacht werden. Zur Überprüfung der Kostendeckung von stationären Chemotherapien wurden die Medikamentenkosten mit ihren Erlösen verglichen. Methode: Von Januar bis Juni 2010 wurde eine retrospektive Kosten-Erlös-Analyse an einer deutschen Universitätsfrauenklinik durchgeführt. Dafür wurde die Liste der stationären Chemotherapien der Klinikumsapotheke für Brustkrebs und Gynäkologische Tumore auf Stimmigkeit überprüft und mit den dokumentierten ZE sowie den Kosten und Erlösen jeder onkologischen Anwendung verglichen. Ergebnisse: $\mathrm{N}=45$ stationäre onkologische Therapien wurden bei $n=18$ Patienten identifiziert und zusätzlich $n=7$ Bisphosphonat-Anwendungen; $\mathrm{n}=11 \mathrm{ZE}$ wurden dokumentiert. Die Kosten für onkologische Medikamente betrugen $33752 €$. Die dazugehörigen ZE-Erlöse betrugen nur $13980 €$, somit resultierte ein Verlust von $19772 €$. Alle stationären onkologischen Therapien waren nicht kostendeckend. Datenabweichungen, fehlerhafte Dokumentation und Kostenzuordnung sowie Prozessabbrüche wurden gefunden. Schlussfolgerungen: Eine regelmäßige finanzielle Qualitätskontrolle an der Schnittstelle von Medizin, Klinikumsapotheke und Verwaltung mit einem monatlichen Vergleich von Kosten und Erlösen sowie Aufnahmestatus wird eingeführt. Nicht kostendeckende stationäre Therapien sollten in ambulante Therapien überführt werden. Die notwendigen Anpassungen der Klinikprozesse werden anhand dieser Ergebnisse durchgeführt, um zukünftige Verluste zu vermeiden.

\section{KARGER \\ Fax +497614520714 \\ Information@Karger.de}

www.karger.com
(C) 2011 S. Karger GmbH, Freiburg 1661-3791/11/0062-0120\$38.00/0
PD Dr. med. Volker R. Jacobs, MBA

Frauenklinik, Universität zu Köln

Kerpener Str. 34, 50931 Köln, Germany

Tel. +49 221 478-4918, Fax -7743

volkerjacobs@hotmail.com 


\section{Introduction}

The German diagnosis-related groups (G-DRGs) provide a system to classify all entities treated on an in-patient basis in German hospitals according to their average resource consumption, and consecutively to reimburse the health care provider accordingly. All procedures in form of operation and procedure codes (OPSs) and the main and side diagnoses from the International Classification of Diseases (ICD)-10 with resource consumption for each in-patient have to be coded individually, by the hospital staff, into a computerbased information system and, after software grouping, lead to a defined DRG. Each DRG has a point value that is multiplied with a so-called base rate to result in the final DRG payment. Since expensive diagnostics and therapies cannot be reflected by such a generalized classification system, a group of up to now $\mathrm{n}=123$ so-called additional payments $(\mathrm{Zu}-$ satzentgelte; ZEs) have been defined by the German Institute for the Hospital Remuneration System (InEK) [1], to cover for the greater part these costs.

The current standard oncological regimens for breast and gynecological cancer can, in general, be performed as out-patient therapies. However, for a variety of reasons, in-patient application of oncological therapies is occasionally performed, but is limited to a few indications. They are primarily based on the individual patient's request or reduced general condition, on private insurance status, or an extended length of hospital stay not allowing postponement of the chemotherapy (CTX) until after discharge. Also off-label use for generally insured patients might be performed on an in-patient basis if a cost-covering $\mathrm{ZE}$ is available.

The increasing cost awareness within German hospitals due to the German flat rate DRG reimbursement system requires a full understanding and active cost management for highly expensive material expenses like for oncological medications [2-4], especially within clinical trials [5, 6]. Hospital costs have to be determined and compared to entity-related revenues in order to provide cost-covering care [7, 8]. Expensive oncological pharmaceuticals [9] are the primary cost drivers for in-patient therapy, which have to be monitored closely [10] to not exceed their reimbursement by ZEs [11]. ZEs are revenues on top of the flat rate DRG payment, e.g. for the application of additional diagnostics or therapies during inpatient care. They are intended to cover the greater part of the costs for some expensive medications, e.g. oncological medication. This is necessary because hospitals have no financial resources to cover losses due to any treatment above their actual revenues. So each individual oncological therapy has to be analyzed from the provider's perspective to determine its cost-effectiveness. Continuous and prolonged financial losses by hospitals can result in a chain reaction leading to deteriorating working conditions, increasing unpaid overtime, losses at the end of the financial year and, finally, privatization of the hospital. Therefore, cost control by routine operative con- trolling tools is necessary, preferably implemented inside an oncological department in order to influence the costs right at the level of care [10].

Previously, cost coverage of in-patient oncological therapies in this clinic was assumed, but never tested and confirmed. To verify cost coverage for in-patient oncological therapies, a comprehensive analysis of performance versus documentation and of cost versus revenues was performed.

\section{Method}

From January to June 2010, a retrospective study was performed at a German obstetrics/gynecology (OB/GYN) university clinic with core competence in gynecological and breast cancer, comparing the hospital's pharmacy list of all in-patient therapies with regard to correctness of in-patient assignment and against all ZE documented. Consecutively, the actual purchase costs and the $\mathrm{ZE}$ revenues for the oncological medication used were compared and the interdisciplinary process of ordering, application, documentation and reimbursement/charge was analyzed. Personnel costs for the entire process were excluded from this evaluation, despite their adding further to any cost imbalance.

The three following data sources of the OB/GYN department were used:

- clinical pharmacy list of all in-patient oncological therapies performed,

- DRG report with all ZE documented and credited for inpatient oncological therapies,

- TOP-75 material expenses account list with in-patient pharmaceutical costs.

The pharmacy list of in-patient oncological therapies was generated from the clinical pharmacy's computer-based order program Cato (Cato Software Solutions $\mathrm{GmbH}$, Austria) as of July 13, 2010. The DRG report from July 5, 2010 including the numbers and revenues of all ZEs from January to June 2010 was generated on a monthly basis by the controlling department of the university hospital's administration and distributed to each clinic and department. Monthly in-patient medication costs come from the TOP-75 material expenses list as of July 16, 2010, including the costs from the pharmacy and/or purchase department. All oncological medications on this list were identified and analyzed. Cost coverage was defined when $\mathrm{ZE} \geq$ costs. Finally, the interdisciplinary process of ordering, application and documentation, and reimbursement was analyzed.

\section{Results}

According to the clinical pharmacy list from January to June $2010, \mathrm{n}=45$ oncological therapies were prepared for $\mathrm{n}=18$ different in-patients in altogether $\mathrm{n}=40$ daily applications at 
the OB/GYN clinic of the University of Cologne. The 45 oncological in-patient applications were: paclitaxel $\mathrm{n}=13$, pegylated liposomal doxorubicine $\left(\right.$ Caelyx $\left.^{\circledR}\right) n=10$, topotecan $\left(\right.$ Hycamtin $\left.^{\circledR}\right) \mathrm{n}=8$, carboplatin $\mathrm{n}=4$, trabectedin $\left(\right.$ Yondelis $^{\circledR}$ ) $\mathrm{n}=3$, etoposide $\mathrm{n}=3$, docetaxel $\left(\right.$ Taxotere $^{\circledR}$ ) $\mathrm{n}=1$, trastuzumab $\left(\right.$ Herceptin $\left.^{\circledR}\right) \mathrm{n}=1$, treosulfan $\left(\right.$ Ovastat $\left.^{\circledR}\right) \mathrm{n}=1$, and gemcitabine $\left(\right.$ Gemzar $\left.^{\circledR}\right) \mathrm{n}=1$. Additionally, $\mathrm{n}=7$ in-patients received bisphosphonates (Ibandronat ${ }^{\circledR}$, Zometa $^{\circledR}$ ).

The clinic's DRG report for the same time frame lists $\mathrm{n}=11$ ZEs as documented and credited: ZE52 liposomal doxorubicine $\left(\right.$ Myocet $\left.^{\circledR}\right) \mathrm{n}=4$, ZE44 topotecan (Hycamtin) $\mathrm{n}=2$, ZE63 paclitaxel $\mathrm{n}=2$, ZE72 pegylated liposomal doxorubicine (Caelyx) $\mathrm{n}=1$, ZE117 trabectedin (Yondelis) $\mathrm{n}=1$, and ZE80 docetaxel (Taxotere) $\mathrm{n}=1$. These 11 CTX cases pertained to $\mathrm{n}=8$ patients with diagnosis of breast cancer $\mathrm{n}=4$ and ovarian cancer $\mathrm{n}=4.2$ patients had 2 CTX at different in-patient stays, 1 patient had 2 CTX in 1 stay. Patient age was on average 57.8 years (42-72 years); length of hospital stay was on average 17.8 days (3-31 days). At least $n=3$ patients were in reduced general state, confirmed by the palliative care code used. The following DRGs were coded: J17Z,
J18Z, $2 \times \mathrm{J} 62 \mathrm{~B}, 2 \times \mathrm{N} 60 \mathrm{~A}, 3 \times \mathrm{N} 60 \mathrm{~B}$, and G46A. 3 patients were privately insured and 5 were generally insured, reflecting a normal distribution in this clinic.

The TOP-75 material expenses lists shows that pharmaceutical costs for in-patient oncological application (material group: antineoplastics and cytostatics) from January to June 2010 amounted to $€ 32,437$. For the same time frame, the DRG report documents ZEs of $€ 13,980$. The application of in-patient oncological therapies resulted for the clinic in an initial loss of $€ 18,457$. The pharmaceutical oncological costs do not equal the $\mathrm{ZE}$ reimbursement, but exceed them by $+132.0 \%$. The in-patient pharmaceutical costs for the application of bisphosphonates (material group: muscle and skeletal system) in $\mathrm{n}=7$ oncological patients with $€ 1315$ were also uncovered, increasing the clinic's loss to $€ 19,772$. However, with $€ 1550$, the calculated costs for all medication (including blood and transfusion) of the DRGs coded here, listed as $4 \mathrm{a}+\mathrm{b}$ in the DRG cost matrix, contributed only marginally to coverage of the clinic's losses. In summary, in-patient therapies performed $\neq$ documented $\mathrm{ZEs} \neq$ hospital's cost $\neq \mathrm{ZE}(+\mathrm{DRG})$ revenues (table 1$)$.

Table 1. Comparison of in-patient oncological therapies performed versus ZE coded and their costs versus revenues, and cost coverage for January to June 2010.

\begin{tabular}{|c|c|c|c|c|c|c|c|c|c|}
\hline Generic name & $\begin{array}{l}\text { Product } \\
\text { name }\end{array}$ & ZE 2010 & $\begin{array}{l}\text { In-patient } \\
\text { therapy } \\
\text { (initial } \\
\text { list), } \mathrm{n}\end{array}$ & $\begin{array}{l}\text { In-patient } \\
\text { therapy } \\
\text { (corrected } \\
\text { list), } \mathrm{n}\end{array}$ & $\begin{array}{l}\text { ZEs docu- } \\
\text { mented } \\
\text { in DRG } \\
\text { report, } \mathrm{n}\end{array}$ & $\begin{array}{l}\mathrm{ZE} \\
\text { revenues, } \\
€\end{array}$ & $\begin{array}{l}\text { Costs, } \\
€\end{array}$ & $\begin{array}{l}\Delta \text { Costs } \\
\text { vs. reve- } \\
\text { nues, } €\end{array}$ & Comments/activities \\
\hline Doxorubicin & $\begin{array}{l}\text { Myocet } \\
\text { (liposomal } \\
\text { doxo- } \\
\text { rubicin) }\end{array}$ & ZE52 & 0 & 0 & 4 & 4117 & 0 & +4117 & $\begin{array}{l}\text { cost-covering, because of unintended cross- } \\
\text { coding of Myocet instead of Caelyx, ZE invoices } \\
\text { are withdrawn }\end{array}$ \\
\hline Doxorubicin & $\begin{array}{l}\text { Caelyx } \\
\text { (pegylated } \\
\text { liposomal } \\
\text { doxo- } \\
\text { rubicin) }\end{array}$ & ZE72 & 10 & 5 & 1 & 843 & 9372 & -8529 & $\begin{array}{l}\text { not cost-covering, } 5 \text { performed as out-patients, } \\
\text { reimbursement of retroactive prescriptions } \\
\text { pending, } 4 \text { ZE retrospectively coded }\end{array}$ \\
\hline Trabectedin & Yondelis & ZE117 & 3 & 1 & 1 & 4147 & 13,951 & -9804 & $\begin{array}{l}\text { not cost-covering, } 2 \text { performed as out-patients, } \\
\text { reimbursement of retroactive prescriptions } \\
\text { pending }\end{array}$ \\
\hline Docetaxel & Taxotere & ZE80 & 1 & 1 & 1 & 1599 & 1754 & -155 & not cost-covering \\
\hline Trastuzumab & Herceptin & ZE27 & 1 & 0 & 0 & 0 & 1803 & -1803 & $\begin{array}{l}\text { not cost-covering, } 1 \text { performed as out-patient, re- } \\
\text { imbursement of retroactive prescription pending }\end{array}$ \\
\hline Topotecan & Hycamtin & ZE44 & 8 & 7 & 2 & 3037 & 4452 & -1415 & $\begin{array}{l}\text { not cost-covering, } 1 \text { performed as out-patient, } \\
\text { reimbursement of retroactive prescription } \\
\text { pending, } 1 \mathrm{ZE} \text { retroactively coded }\end{array}$ \\
\hline Paclitaxel & Taxol & ZE63 & 13 & 10 & 2 & 237 & 384 & -147 & $\begin{array}{l}\text { not cost-covering, thresholds for } \mathrm{ZE} \text { of } \geq 180 \mathrm{mg} \\
\text { not reached; } 3 \text { performed as out-patients, } \\
\text { reimbursement of retroactive prescriptions } \\
\text { pending; } 1 \mathrm{ZE} \text { retroactively coded }\end{array}$ \\
\hline Gemcitabine & Gemzar & ZE17 & 1 & 1 & 0 & 0 & 138 & -138 & $\begin{array}{l}\text { not cost-covering, threshold for } \mathrm{ZE} \text { of } \geq 2.5 \mathrm{~g} \\
\text { not reached }\end{array}$ \\
\hline Carboplatin & & - & 4 & 4 & 0 & 0 & 30 & -30 & not cost-covering, but costs negligible \\
\hline Etoposide & & - & 3 & 3 & 0 & 0 & 37 & -37 & not cost-covering, but costs negligible \\
\hline Treosulfan & Ovastat & - & 1 & 1 & 0 & 0 & 516 & -516 & not cost-covering \\
\hline$\sum$ & & & 45 & 33 & 11 & 13,980 & 32,437 & $-18,457$ & \\
\hline Bisphosphonates & $\begin{array}{l}\text { Ibandronat, } \\
\text { Zometa }\end{array}$ & - & 7 & 7 & 0 & 0 & 1315 & -1315 & not cost-covering \\
\hline$\sum$ & & & 52 & 40 & 11 & 13,980 & 33,752 & $-19,772$ & \\
\hline
\end{tabular}

ZE documented und ZE revenues, costs and $\Delta$ costs refer to the initial in-patient therapy list. 


\section{Analysis of Problems in the In-Patient Oncological Therapy Process}

The discovered complex discrepancies led to a detailed analysis of all in-patient oncological therapies and of the process of ordering, documentation, cost attribution, coding, and reimbursement, with the identification of the following main problems.

\section{Incorrect Pharmaceutical Order as In-Patient instead of Out-Patient}

A reevaluation of the pharmacy's in-patient list revealed that $n=12 / 45(26.7 \%)$ of the oncological therapies were ordered for in-patients although the application was actually in an out-patient setting. The reason was an input mistake by the corresponding physician when ordering the CTX through the Cato software; thus, in the menu, an already expired admission status as in-patient was not changed to out-patient (fig. 1 (1)). All therapies classified by mistake as in-patients therapies $(\mathrm{n}=12 ; 5 \times$ liposomal doxorubicin, $3 \times$ paclitaxel, $2 \times$ trabectedin, $1 \times$ topotecan, $1 \times$ trastuzumab) were identified, the admission status was changed to out-patient, and prescriptions of a value of $€ 24,645$ (including concomitant medication) were retroactively issued. As a positive side effect, the pharmaceutical costs were reattributed from the clinic's in-patient to the out-patient cost account, thereby reducing the material expenses of the entire clinic for all in-patients by about $2 \%$ per year.

\section{Abort of Reimbursement Process for Incorrect \\ In-Patient Therapies}

The reimbursement process initiated by medical coders after discharge of in-patients who underwent oncological therapy is triggered by the in-patient admission into the computer system and registration in an existing in-patient medical chart (fig. 1, Trigger). An incorrect oncological order as in-patient therapy resulted in booking of costs into the in-patient cost account without any further measures, finally resulting in a complete abortion of any reimbursement process (fig. 1 (2)). Due to non-existing triggers for reimbursement for incorrectly classified in-patient therapies, $26.7 \%$ of all in-patient CTX in the first half of 2010 were at this point not accounted for.

\section{Documentation Errors of Oncological ZEs}

A comparison between in-patient therapies performed and the corresponding documented ZEs revealed that $n=4$ ZE52 for Myocet were documented but not performed. The same number of ZE72 was underdocumented for Caelyx. This could be explained by the fact that Caelyx is pegylated liposomal doxorubicin and Myocet is plain liposomal doxorubicin, a pharmacological difference only oncology specialists are familiar with. Caelyx application was therefore incorrectly coded as Myocet application. Internal lists of medical coding as well as from the clinical pharmacy had misleading informa-

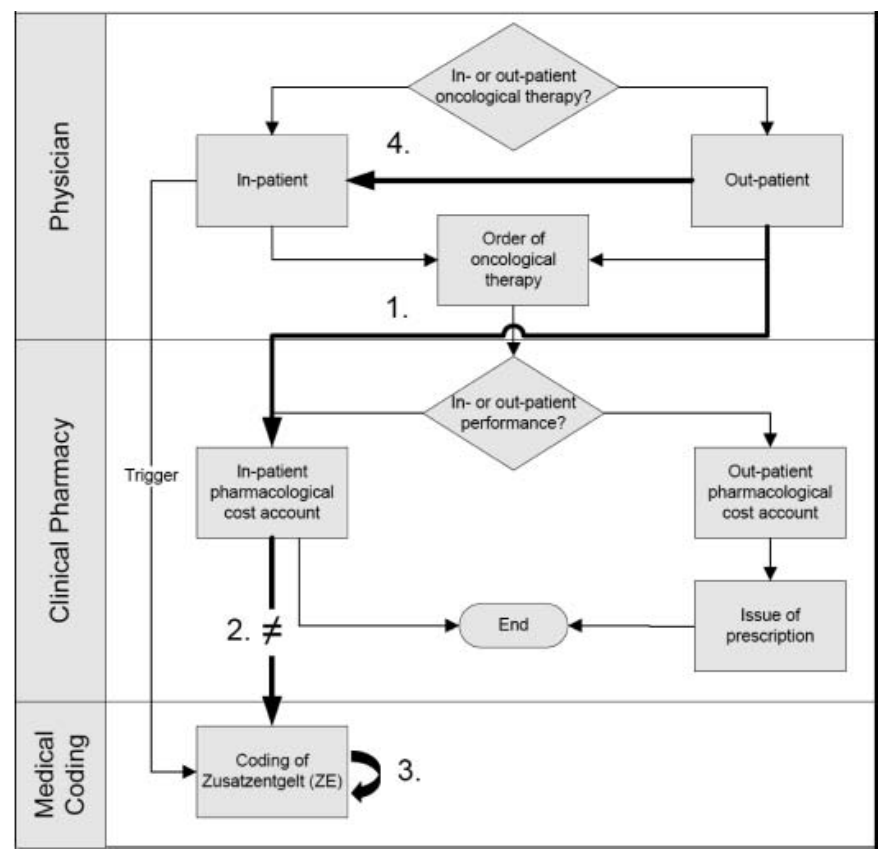

Fig. 1. Analysis of process problems with in-patient oncological therapies.

tion regarding this aspect and contributed to this error (fig. 1 (3)). Additionally, 2 in-patient therapies were identified as initially not ZE-coded $(1 \times$ topotecan and $1 \times$ paclitaxel $)$.

\section{Application of Non-Cost-Covering In-Patient Therapy}

The decision of a physician for in-patient application of CTX is normally not based on reimbursement aspects. However, it can be an economical mistake to apply oncological therapies in an in-patient setting (fig. 1 (4)). The main reasons for noncost-covering in-patient pharmacological therapy are that (1) oncological therapies do not qualify for $\mathrm{ZE}$ : carboplatin $\mathrm{n}=4$, treosulfan (Ovastat) $n=1$, etoposide $n=3$, and bisphosphonates $\mathrm{n}=7$ (Ibandronat, Zometa); (2) initial threshold values for generation of a $\mathrm{ZE}$ are not reached with a single application; and (3) independently of the possibility of a ZE code, each substance has to be evaluated in advance for cost coverage in in-patient use because ZEs do neither assure nor intend to be completely cost-covering.

\section{Discussion}

The financial quality control of in-patient oncological therapies for breast and gynecological cancer performed at the $\mathrm{OB} /$ GYN department of the University of Cologne from January to June 2010 showed that all oncological pharmaceuticals used are not cost-covering from the provider's perspective with regard to the ZEs generated. The only cost-covering medication (Myocet) was actually not given, but is in the plus due to a documentation error which will be retroactively 
corrected. So the calculated loss is even underestimated when the ZE for Myocet is deducted and a lower ZE for Caelyx is credited. Some standard oncological medications used do not have additional payments in the form of ZEs at all (carboplatin, etoposide, treosulfan, and bisphosphonates). Most ZEs have complicated threshold values that have to be reached first, which can be impossible with single-dose applications, e.g. thresholds for paclitaxel of $\geq 180 \mathrm{mg}$ and gemcitabine (Gemzar) of $\geq 2.5 \mathrm{~g}$. And if threshold values are reached to generate a $\mathrm{ZE}$, the revenues are not in all cases cost-covering, as demonstrated, because they are lower than the actual purchase costs. Additionally, a rigid stepwise increase of ZEs, not reflecting the patients' individual dose and costs, contributes to a cost-ineffective application. This evaluation shows that hospitals cannot be sure that the current DRG reimbursement system for in-patient use of expensive medication is adequate or even complete. Since costs for newer bisphosphonates with about 200 per application are not reimbursed at all within the DRG system or by ZEs or other means, the inpatient application of expensive bisphosphonates should be abandoned and preferably be postponed until the next possible out-patient application. This is supported by the fact that bisphosphonates have no emergency indication and that recently the length of in-patient stays, especially for most breast cancer patients, has been dramatically reduced. So an intended application scheme of q21 or q28 can usually be postponed until a few days after discharge from the hospital. Financially optimal application of bisphosphonates is exclusively given in the out-patient setting, for which the patient has to stay at home the nights before and after therapy. Therefore, hospitals should carefully analyze in advance if any oncological therapies can be performed in a cost-covering way on in-patients in Germany. In most cases analyzed here, in-patient CTX could not be avoided due to an extended length of hospital stay. But financial quality controls on a routine base - analogous to the already established medical quality controls - is suggested to assure cost coverage, data and coding accuracy, and to consecutively adjust the cost of care to the revenues from the provider's perspective.

However, a deeper analysis of the processes at the interface of medicine and organization within the hospital showed that there are multiple and complex organizational problems contributing to cost-ineffective in-patient oncological therapies. Missing information and lack of communication, undefined responsibility, and lack of integration of medical and economical aspects, including a missing overall process responsibility, contribute to the situation. As a consequence of this study, the following measures were initiated: Retroactive measures: (1) change of incorrect in-patient to correct out-patient admission status; (2) consecutively, change of costs from in-patient to out-patient account; (3) consecutive retroactive issuing of oncological pharmaceutical prescriptions of about $€ 24,645$ (comedication included, but still risk of non-reimbursement for $\mathrm{OB} / \mathrm{GYN}$ clinic); and (4) correc- tion of mistakenly miscoded ZEs. Prospective measures: (1) pharmacy lists of in-patient oncological therapies will be evaluated monthly on a routine base to verify adequate admission status and to timely eliminate potential mistakes; (2) monthly comparison of generated ZEs from the DRG report with costs from the TOP-75 material expenses list; and (3) training of all medical and supporting staff with regard to adjustment options of oncological costs and revenues plus correction of internal lists, including information for clinicians as to which oncological therapies are cost-covering or not. Thresholds for oncological reimbursement should be addressed and consistently applied in the daily clinical routine to identify and reduce, and eventually avoid, the performance of therapies that are non-cost-covering from the provider's perspective.

Furthermore, to avoid the presently unstructured coding by medical coders who, after discharge, may identify ZE medication in medical patient charts by chance or not, $100 \%$ accuracy of coding of ZEs can only be guarantied when coding is performed correctly right at the place of issue, the clinical pharmacy, straight into a computer-based clinic information system and/or patient file for the in-patient invoice. This leaves coding not at random, assures a 100\% correct coding rate and can verify the adequate admission and order status of in-patient versus out-patient and, at the same time, cost attribution of pharmaceuticals into correct in- or out-patient accounts. The best time for this would be the following morning after application, allowing timely identification and correction of potential process mistakes immediately after discharge. Additional expenses for such a staff position in the clinical pharmacy will be easily covered by instant reductions of previous losses and provide an excellent return on investment for the provider.

In this study, in-patient oncological therapies have been shown to be financially unattractive for the provider. Since they are not really necessary and can be avoided by active process steering, they should be handled accordingly. Multiple financial risks - one-sided on the health care provider's side - make expensive in-patient oncological therapies financially extremely unattractive. These risks are, e.g., the order of a CTX at the expense of the hospital but with the patient not showing up or without performance of the CTX (e.g. due to a sudden change in the patient's health status), expiry of medication, unusable residual drugs for some package sizes, patient bankruptcy or non-payment of hospital bills, regress through sickness fund due to retroactive non-approval for in-patient therapy, etc. Taking the financial risk for expensive in-patient therapies has no financial benefits; the risks by far outweigh the limited to non-existent rewards. In-patient oncological therapy in the current reimbursement system should therefore be abandoned for economical reasons. However, to serve the patients' needs, in-patient oncological therapy might be an option for selected cases if reimbursement by ZEs is possible without financial loss. 
This example of missing and/or inefficient economic process steering led to an overproportional financial loss for the hospital, and not for the insurance companies as often proclaimed by the health insurers and the media $[12,13]$. The inconsistencies in documentation and reimbursement discovered here were due to missing routine operative controlling at the interface between medicine and administration. No systematic or even intended mistakes to the financial disadvantage of basic health sickness funds and health insurances were found; however, discrepancies in the performance of oncological therapies and underdocumented as well as underreimbursed oncological therapies led to such a remarkable loss for the hospital provider that it may be only partially compensated for.
Limitations of this study are that costs for comedication and personnel were not included and investigated; however, they are considered to be rather small in contrast to the much higher oncological medication costs. Also, DRG subrevenues for medication were not deducted from the loss, but any revenues for medication included in the DRGs almost exclusively cover only basic medication, and expensive medication is commonly not included in the DRGs. Therefore, both effects are considered to be negligible for the results of this study.

\section{Disclosure Statement}

The authors declare no conflict of interest.

\section{References}

1 Institute for the Hospital Remuneration System (InEK): www.g-drg.de.

2 Jacobs VR, Thoedtmann J, Brunner B, Kiechle $\mathrm{M}$ : An economic model to reduce the cost of chemotherapy for gynecologic cancer. Int J Fertil Womens Med 2004:49:274-277.

3 Jacobs VR, Thoedtmann J, Euler U, Paepke S, Fischer T, Harbeck N, Kiechle M: Physician-based active cost management of oncological therapies reducing pharmaceutical costs by $83.4 \%$ in two years without leaving standard of care. Onkologie 2005;28:441-445.

4 Jacobs VR, Thödtmann J, Brunner B, Kiechle M Modell eines aktiven Kostenmanagements gynäkoonkologischer Therapien zur Reduktion der Medikamentenkosten um 58.7\% innerhalb eines Jahres. Geburtshilfe Frauenheilkd 2005;65:46-55.

5 Jacobs VR: Making or losing money with participation in clinical trials: a decision analysis. Onkologie 2009;32:411-416.

6 Braun M, Jacobs VR, Wagenpfeil S, Sattler D, Harbeck N, Nitz U, Bernard R, Kuhn W, IhbeHeffinger A: Cost analysis comparing an anthracycline/docetaxel regimen to CMF in patients with early stage breast cancer. Onkologie 2009;32:473481.
7 Ihbe-Heffinger A, Paessens BJ, von Schilling C, Shlaen M, Gottschalk N, Berger K, Bernard R, Kiechle M, Peschel C, Jacobs VR: Management of febrile neutropenia - A German prospective hospital cost analysis in lymphoproliferative disorders, non-small cell lung cancer, and primary breast cancer. Onkologie 2011; 34:241-246.

8 Jacobs VR, Mayer SC, Paessens BJ, Bernard R, Harbeck N, Kiechle M, Ihbe-Heffinger A: Comparison of actual hospital costs vs. DRG revenues for in-patient treatment of febrile neutropenia during adjuvant anthracycline \pm taxane-based CTX for primary breast cancer. Onkologie 2011, submitted.

9 Jacobs VR: Current status of financing and reimbursement of Herceptin (trastuzumab) for adjuvant and advanced therapy of breast cancer in germany. Breast Care 2006;1:86-94.

10 Jacobs VR, Mallmann P: Chief medical clinic manager of a university OB/GYN clinic - an innovative job description as management response for increase of profitability, quality of care, and physicians' freedom of action. Onkologie 2010;33:331336.
11 Institute for the Hospital Remuneration System (InEK): Fallpauschalenkatalog, G-DRG-Version 2010, Anlage 2: Zusatzentgelte-Katalog Liste, S. 129-130, und Anlage 5: Zusatzentgelte-Katalog Definition und differenzierte Beträge, S. 136-158, 30.09.2009. www.g-drg.de/cms/index.php/inek_site_ de/G-DRG-System_2010/Fallpauschalen-Katalog/ Fallpauschalen-Katalog_2010.

12 Elger K, Ludwig U, Neumann C: Ein modernes Massendelikt. [A modern widespread criminal offence.] Der Spiegel 2010;64:32-34.

13 Fiori W, Bunzemeier H, Roeder N: Abrechnungsbetrug der Krankenhäuser? Medienkampagne der Krankenkassen geht in die falsche Richtung. [Reimbursement fraud by hospitals? Media campaign of sickness funds heading into the wrong direction.] Das Krankenhaus 2010;102:621-628. 